\title{
Influence of aspirin on the CX3CL1/CX3CR1 signaling pathway in acute pulmonary embolism
}

\author{
ZHIRONG ZHANG ${ }^{1 *}$, WEIJI YANG ${ }^{2 *}$, RONGBIAO YING $^{3 *}$, YING SHI $^{1 *}$, HUIFANG JIANG $^{4 *}$, \\ DANLI CAI $^{*}$, JING KUANG $^{1 *}$, RUHUI YANG $^{5^{*}}$ and LINGCONG WANG ${ }^{1}$
}

\author{
${ }^{1}$ Department of ICU, The First Affiliated Hospital of Zhejiang Chinese Medical University, Hangzhou, Zhejiang 310006; \\ ${ }^{2}$ Postgraduates Department of Zhejiang Chinese Medical University, Hangzhou, Zhejiang 310053; ${ }^{3}$ Department of Surgical Oncology, \\ Tumor Hospital of Taizhou, Wenling, Zhejiang 317500; ${ }^{4}$ Department of Hematology, Tongde Hospital of Zhejiang, \\ Hangzhou, Zhejiang 310012; ${ }^{5}$ College of Medicine and Health, Lishui University, Lishui, Zhejiang 323000, P.R. China
}

Received August 31, 2016; Accepted April 19, 2017

DOI: $10.3892 /$ ijmm.2017.2969

\begin{abstract}
The present study aimed to explore the influence of aspirin on the CX3CL1/CX3CR1 signaling pathway in acute pulmonary embolism (APE) in rats. Our previous study found that $\mathrm{CX} 3 \mathrm{CL} 1 / \mathrm{CX} 3 \mathrm{CR} 1$ was increased in APE. However, the effect of this signaling pathway on APE remains unclear. CX3CL1-shRNA adenovirus and CX3CL1-overexpression vector were constructed. Male Sprague-Dawley rats were randomly divided into 9 groups $(n=10)$ : normal group (group N), sham operation group (group Sham), sham operation + aspirin group (group ASP), model group (group M), model + ASP group (group $\mathrm{M}+\mathrm{A})$, model + shRNA group (group $\mathrm{M}+\mathrm{SH}$ ), sham operation $+\mathrm{CX} 3 \mathrm{CL} 1-o v e r e x p r e s s i o n$ vector group (group Sham+Cx3), model + ASP + shRNA group (group $\mathrm{M}+\mathrm{A}+\mathrm{SH}$ ), and model + ASP + CX3CL1overexpression vector group (group $\mathrm{M}+\mathrm{A}+\mathrm{CX} 3$ ). Arterial
\end{abstract}

Correspondence to: Dr Lingcong Wang, Department of ICU, The First Affiliated Hospital of Zhejiang Chinese Medical University, 54 Youdian Road, Hangzhou, Zhejiang 310006, P.R. China E-mail:wlc501@139.com

*Contributed equally

Abbreviations: APE, acute pulmonary embolism; HR, heart rate; TNF- $\alpha$, tumor necrosis factor- $\alpha$; IL, interleukin; NF, nuclear factor; ERK, extracellular signal-regulated kinase; BNP, brain natriuretic peptide; TnT, troponin T; MMP, matrix metallopeptidase; shRNA, short hairpin RNA; RT-PCR, reverse transcription-polymerase chain reaction; ELISA, enzyme-linked immunosorbent assay; $\mathrm{SD}$, Sprague-Dawley; MCMV, murine cytomegalovirus; GFP, green fluorescent protein; $\mathrm{H} \& \mathrm{E}$, hematoxylin and eosin staining; TXA2, thromboxane A2; TNNI3, troponin I type 3; D2D, D-dimer; ICAM, intercellular adhesion molecule; AD, adenovirus; PASP, pulmonary arterial systolic pressure; PADP, pulmonary artery diastolic pressure; PAP, pulmonary arterial pressure; VTE, venous thromboembolism

Key words: aspirin, CX3CL1, CX3CR1, nuclear factor- $\kappa \mathrm{B}$, pulmonary embolism pressure detection, hematoxylin and eosin staining, reverse transcription-polymerase chain reaction, enzyme-linked immunosorbent assay, and laser confocal scanning microscopy were applied. Aspirin significantly decreased pulmonary artery pressure, improve pathological changes in the embolism, and decreased the expression of CX3CL1/CX3CR1 and $\mathrm{CX} 3 \mathrm{CL} 1 / \mathrm{NF}-\kappa \mathrm{B}$. Moreover, the adenovirus-overexpression CX3CL1 vector aggravated the inflammatory changes in APE, which were improved by aspirin. However, the intervention of the adenovirus CX3CL1 vector reduced the change, while its combination with aspirin significantly improved the change. In conclusion, aspirin improved pathological changes in rats with APE via the CX3CL1/CX3CR1 signaling pathway.

\section{Introduction}

Acute pulmonary embolism (APE) is a disease caused by various emboli blocking the pulmonary artery, leading to pulmonary circulation disorder. The morbidity and fatality rate are high in European and American countries, and have increased in recent years. The morbidity in the United States during 1979-1999 was reported to be $0.4 \%$, and $\sim 150,000$ individuals are hospitalized due to APE every year. There was no obvious change in 20 years (1). The epidemiology of APE is difficult to confirm due to the lack of symptoms and proper diagnosis. In 2004, according to the demographic statistics of 454.4 million people in 6 countries of the European Union, 317,000 deaths related to venous thrombus were reported. Among them, 34\% died of acute fat embolism, 59\% died of APE (diagnosed by autopsy, not alive), and only $7 \%$ were diagnosed with APE prior to death (2). In China, of the 16,972,182 hospitalized patients, 18,206 patients had APE. The annual occurrence rate is $0.1 \%$, and the incidence is significantly higher in males $(0.2 \%)$ than in females $(0.1 \%)$. The fatality decreased from $25.1 \%$ in 1997 to $8.7 \%$ in 2008 (3). APE has become a common cardiovascular disease in China, seriously threatening human health. Thus, interventions are urgently needed.

Previous research found that the levels of tumor necrosis factor- $\alpha$ (TNF- $\alpha)$, interleukin-1 $\beta$ (IL-1 $\beta)$, IL-8, CX3CL1, 
CX3CR1, nuclear factor- $\kappa \mathrm{B}(\mathrm{NF}-\kappa \mathrm{B})$, extracellular signalregulated kinase $(\mathrm{ERK}), \mathrm{PI} 3 \mathrm{~K} / \mathrm{Akt}$, brain natriuretic peptide (BNP), troponin T (TnT) and D-dimer (D2D) were significantly increased in APE rat models (4-6). The increased CX3CL1 level in serum was found to have a positive correlation with serum IL- 8 and TNF- $\alpha$, and aspirin significantly inhibited all the aforementioned factors. Meanwhile, it was also found that aspirin could inhibit lipopolysaccharide and induce the expression of PI3K, Akt, ERK, NF- $\mathrm{B}, \mathrm{CX} 3 \mathrm{CL} 1$, matrix metallopeptidase-7 (MMP-7) and MMP-12 in human bronchial epithelial cells (7). Therefore, it is believed that the inflammatory response occurs in APE, CX3CL1/CX3CR1 significantly increases, and TNF- $\alpha$ stimulates CX3CL1, and aspirin can inhibit the aforementioned factors. However, the effect of the CX3CL1/CX3CR1 signaling pathway on the occurrence of APE remains unclear.

In the present study, CX3CL1-short hairpin RNA (shRNA) adenovirus (AD) and CX3CL1-overexpression vector were constructed. Reverse transcription-polymerase chain reaction (RT-PCR), enzyme-linked immunosorbent assay (ELISA), laser confocal scanning microscopy, and pulmonary artery pressure detection were applied to explore the protective effect of aspirin on APE via the CX3CL1/CX3CR1 signaling pathway in an animal model.

\section{Materials and methods}

Materials. Enteric-coated aspirin tablets were procured from Nanjing Baijingyu Pharmaceutical Co., Ltd. (Jiangsu, China; drug specifications: 25 mg x 100 pills/bottle, batch no. 141201).

Male Sprague-Dawley (SD) rats (200 g) were purchased from Shanghai SLAC Laboratory Animal Co., Ltd. (Shanghai, China) and Vital River Laboratories Co., Ltd. (Beijing, China). The feeding temperature was $20-25^{\circ} \mathrm{C}$, and the humidity was 40-70\%. After a 6-day acclimation, the experiment was intiated. The study was approved by the Ethics Committee of Zhejiang Chinese Medical University.

Construction of the CX3CL1-overexpression vector and shRNA was performed. Vector pHBAd-murine cytomegalovirus (MCMV)-green fluorescent protein (GFP) and vector pHBAd-U6-GFP (Hanbio, Hangzhou, China) were used. Escherichia coli strain DH5 $\alpha$ (Tiangen, Beijing, China), restriction enzymes, T4 ligase (both from Fermentas, Waltham, MA, USA), and plasmid DNA extraction kit (CWBio, Beijing, China) were used.

Biological function experimental system (BL-420S) and animal ventilator (HX-300) were obtained from Taimeng (Sichuan, China). Multiskan spectrum microplate spectrophotometer (Spectra Plus 384) was purchased from Molecular Devices (Sunnyvale, CA, USA).

Hematoxylin and eosin staining (H\&E) was used to observe histopathological changes in the pulmonary tissue.

Thromboxane A2 (TXA2), troponin I type 3 (TNNI3), BNP and D2D levels in rat serum were detected using ELISA. TTNNI3kit, BNP, TXA2 and D2D were obtained from Youershengke (Wuhan, China).

RT-PCR was used to detect CX3CL1, CX3CR1 and intercellular adhesion molecule-1 (ICAM-1) expression in mRNA of rat pulmonary tissue. A high-purity total RNA rapid extraction kit was obtained from Generay (Shanghai, China), and a PrimeScript RT reagent kit was purchased from Takara (Tokyo, Japan). Super Real PreMix Plus (with SYBR-Green I) was obtained from Tiangen. High-precision spectrophotometer (Merinton SMA4000; Merinton Instrument, Ltd., Beijing, China) and quantitative PCR system (CFX connect real-time PCR system; Bio-Rad, Hercules, CA, USA) were used.

Laser confocal scanning microscopy was used to detect the coexpression of $\mathrm{CX} 3 \mathrm{CL} 1 / \mathrm{CX} 3 \mathrm{CR} 1$ and $\mathrm{CX} 3 \mathrm{CL} 1 /$ NF- $\kappa$ B. Fractalkine antibody (CX3CL1) (cat. no. sc-7227; batch no. B1612; 1:10; Santa Cruz Biotechnology, Inc., Santa Cruz, CA, USA), anti-NF-кB p65 antibody (cat. no. ab7970; batch no. GR187946-6; 1:50), anti-CX3CR1 antibody (cat. no. ab8021; batch no. GR90085-11; 1:100) (both from Abcam, Cambridge, MA, USA), anti-rabbit IgG secondary antibody (cat. no. A21206; batch no. 1110071; 488 conjugate; Life Technologies, Carlsbad, CA, USA; excitation wavelength/emission wavelength: 488/520 nm, 1:200), anti-goat IgG secondary antibody (cat. no. A21432; batch no. 1620248; 555 conjugate; excitation wavelength/emission wavelength: 555/562 nm, 1:200) (Life Technologies), 4',6-diamidino-2-phenylindole (DAPI) (excitation wavelength/emission wavelength: 358/461 nm; Sigma, St. Louis, MO, USA) were used.

\section{Methods}

Preparation of the CX3CL1-overexpression vector and shRNA. The steps for construction of CX3CL1 overexpression AD are as follows. AD vector plasmid was recombined and pHBAdMCMV-GFP vector was digested with EcoRI and BamHI double enzymes and collected after digestion. CX3CL1 fragments were obtained, and the transformed CX3CL1 was used to select bacterial colonies. The bacteria were incubated by shaking for $14 \mathrm{~h}$ at $37^{\circ} \mathrm{C}$ and $250 \mathrm{rpm}$. The bacterial suspension was detected using PCR and sequenced to obtain pHBAd-MCMVGFP-CX3CL1 recombinant vector, marked as AD-CX3CL1. Meanwhile, plasmid pHBAd-MCMV-GFP was used as the control, and marked as AD-GFP. Recombinant plasmids and recombinant $\mathrm{AD}$ vector package were prepared. Then, virus harvesting, amplification, purification, and detection of the infectious titer were performed. CX3CL1 shRNA AD construction process was as follows. pHBAd-U6-GFP interference vector was used, and the interference sequence was designed to construct, screen and identify CX3CL1 shRNA (Fig. 1).

Animal model. Male SD rats $(200 \pm 20 \mathrm{~g})$ were randomly divided into 9 groups $(n=10)$ : normal group (group $N)$, sham operation group (group Sham), sham operation + aspirin group (group ASP), model group (group M), model + ASP group (group M+A), model + shRNA (group $\mathrm{M}+\mathrm{SH}$ ), sham operation + CX3CL1-overexpression vector group (group Sham $+\mathrm{CX} 3$ ), model + ASP + shRNA group (group $\mathrm{M}+\mathrm{A}+\mathrm{SH}$ ), and model + ASP + CX3CL1overexpression vector group (group $\mathrm{M}+\mathrm{A}+\mathrm{CX} 3$ ). Autologous thrombus was injected through the jugular vein to copy a rat PTE model. One day before surgery, $0.2 \mathrm{ml}$ of blood was withdrawn from the caudal vein, and incubated at $37^{\circ} \mathrm{C}$ overnight. The concretionary thrombus was taken out to prepare 30 emboli $\left(2 \times 1 \mathrm{~mm}^{2}\right)$, which were further placed into a 2-ml syringe. The rats were anesthetized using $10 \%$ chloral hydrate $(0.3 \mathrm{~g} / \mathrm{kg})$. The right jugular vein was separated, and the puncture needle was placed. The prepared embolus was pushed into the common vein using the puncture needle, followed by 

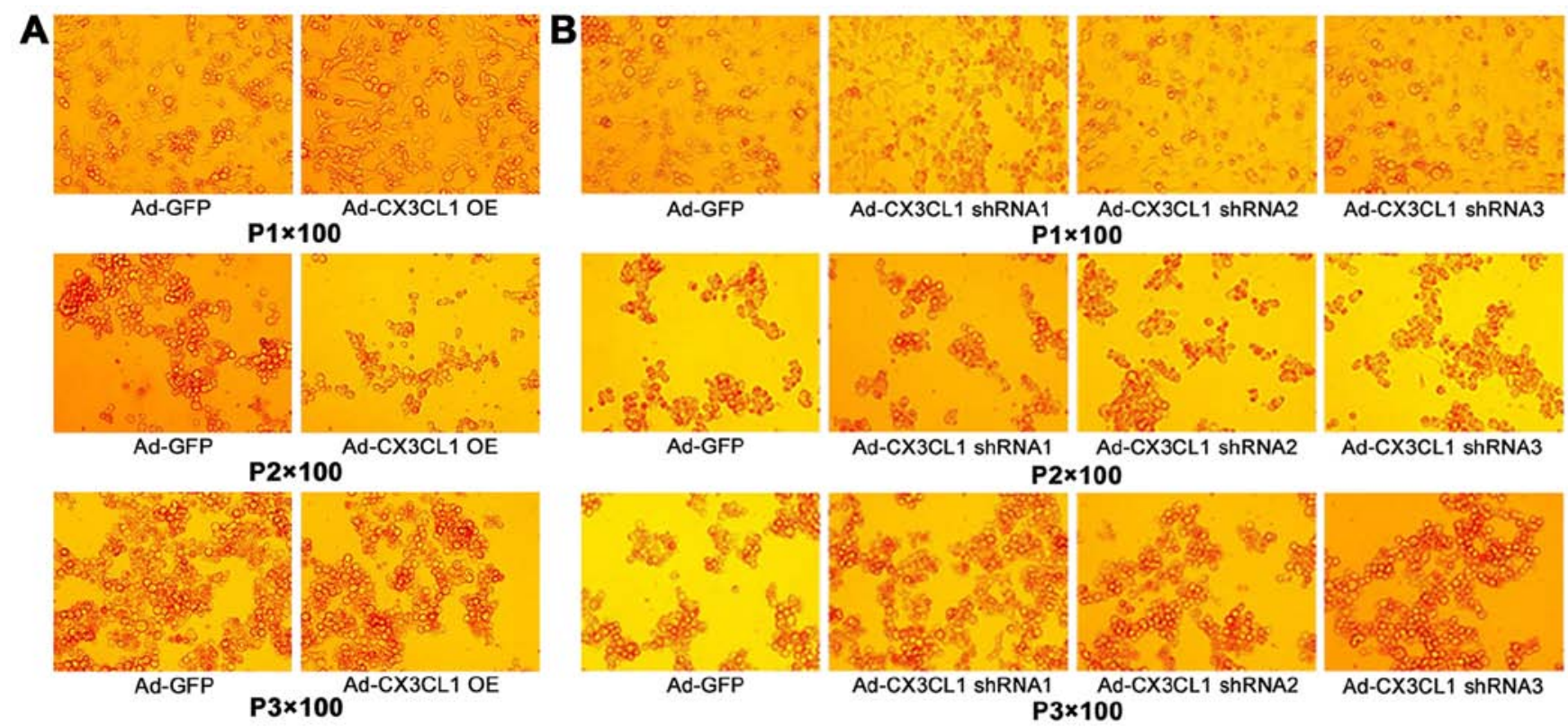

Figure 1. (A) Construction of the CX3CL1-overexpression adenovirus. (B) CX3CL1 short hairpin RNA (shRNA) adenovirus construction.

pushing $1 \mathrm{ml}$ of saline to prevent the embolus from staying in the tube or jugular vein. Finally, the wound was sutured after the bleeding stopped. One day before surgery and $40 \mathrm{~min}$ before modeling, the drug was administrated via gavage. The virus intervention groups (group $\mathrm{M}+\mathrm{SH}$, group Sham $+\mathrm{CX} 3$, group $\mathrm{M}+\mathrm{A}+\mathrm{SH}$, group $\mathrm{M}+\mathrm{A}+\mathrm{CX} 3$ ) were injected once with aspirin $300 \mathrm{mg} / \mathrm{kg}$ through the caudal vein 3 days before modeling (109 pfu/rat). Group Sham and group M received an equal volume of saline every day. Group $\mathrm{N}$ did not receive any intervention.

Detection of pulmonary artery pressure. Six hours after modeling, the animals were anesthetized again. A PE50 tube was inserted into the pulmonary artery, and the other side was connected with a pressure transducer. A waveform of pulmonary artery pressure was recorded using the biological function experimental system (BL-420S), and pulmonary arterial systolic pressure (PASP), pulmonary artery diastolic pressure (PADP) and pulmonary arterial pressure (PAP) were calculated.

Pulmonary pathology was detected using H\&E staining and CX3CL1, CX3CR1 and ICAM-1 in pulmonary tissue were detected by RT-PCR.

TXA2, BNP, TNNI3 and D-dimer in serum were detected by double-antibody sandwich or competitive inhibition ELISA.

CX3CL1/CX3CR1 coexpression and CX3CL1/NF- $\kappa \mathrm{B}$ coexpression in the pulmonary tissue were detected by laser confocal scanning microscopy.

The virus intervention group was divided into two subgroups (CX3CL1-overexpression group and shRNA group). The tissue was cut into $8-\mu \mathrm{m}$ slices at $-20^{\circ} \mathrm{C}$ and observed by a fluorescence microscope.

Statistical analysis. SPSS 21.0 (SPSS, Chicago, IL, USA) was used for data analysis, and the results are expressed as mean \pm standard deviation. One-way analysis of variance was used, and pairwise comparison between groups was analyzed by least significant difference. A P-value $<0.0$ was considered to indicate a statistically significant result.

\section{Results}

Detection of pulmonary artery pressure. Compared with group $\mathrm{N}$, hear rate (HR), PASP, PADP and PAP in group M were significantly increased $(\mathrm{P}<0.05)$. PASP and PAP in group Sham $+\mathrm{CX} 3$ were significantly increased $(\mathrm{P}<0.05)$. Compared with group $\mathrm{M}, \mathrm{HR}$ in group $\mathrm{M}+\mathrm{A}$ was significantly decreased $(\mathrm{P}<0.05)$, PASP in groups $\mathrm{M}+\mathrm{A}+\mathrm{SH}$, ASP and $\mathrm{M}+\mathrm{A}+\mathrm{CX} 3$ were also significantly decreased $(\mathrm{P}<0.05)$. PADP and PAP in groups $\mathrm{ASP}, \mathrm{M}+\mathrm{A}, \mathrm{M}+\mathrm{A}+\mathrm{SH}$, and $\mathrm{M}+\mathrm{A}+\mathrm{CX} 3$ were significantly decreased $(\mathrm{P}<0.05)$ (Fig. 2).

Pulmonary $H \& E$ detection. The results of lung pathology as detected by H\&E are shown in Table I and Fig. 3.

CX3CL1, CX3CR1 and ICAM-1 in the pulmonary tissue as detected by PCR. As shown in Fig. 4, compared with group $\mathrm{N}$, CX3CL1 in groups $\mathrm{M}$, Sham+CX3, $\mathrm{M}+\mathrm{A}+\mathrm{SH}$ and $\mathrm{M}+\mathrm{A}+\mathrm{CX} 3$ was significantly increased $(\mathrm{P}<0.05)$. Compared with group $\mathrm{M}$, CX3CL1 in groups $\mathrm{N}$, Sham, M+SH, ASP and M+A was significantly decreased $(\mathrm{P}<0.05)$.

The comparisons of CX3CR1 among the different groups showed no significant differences.

Compared with group N, ICAM-1 in groups Sham+CX3, $\mathrm{M}+\mathrm{A}+\mathrm{SH}$ and $\mathrm{M}+\mathrm{A}+\mathrm{CX} 3$ was significantly increased $(\mathrm{P}<0.05)$. Compared with group M, ICAM-1 in group Sham+CX3 was significantly decreased $(\mathrm{P}<0.05)$.

TXA2, TNNI3, BNP and D2D levels in rat serum as detected by ELISA. As shown in Fig. 5, compared with group N, TXA2 in group $\mathrm{M}$ was significantly increased $(\mathrm{P}<0.05)$. Compared with group $\mathrm{M}$, TXA2 in groups $\mathrm{N}$, Sham, $\mathrm{M}+\mathrm{SH}, \mathrm{ASP}, \mathrm{M}+\mathrm{A}$ and $\mathrm{M}+\mathrm{A}+\mathrm{SH}$ was significantly decreased $(\mathrm{P}<0.05)$. 

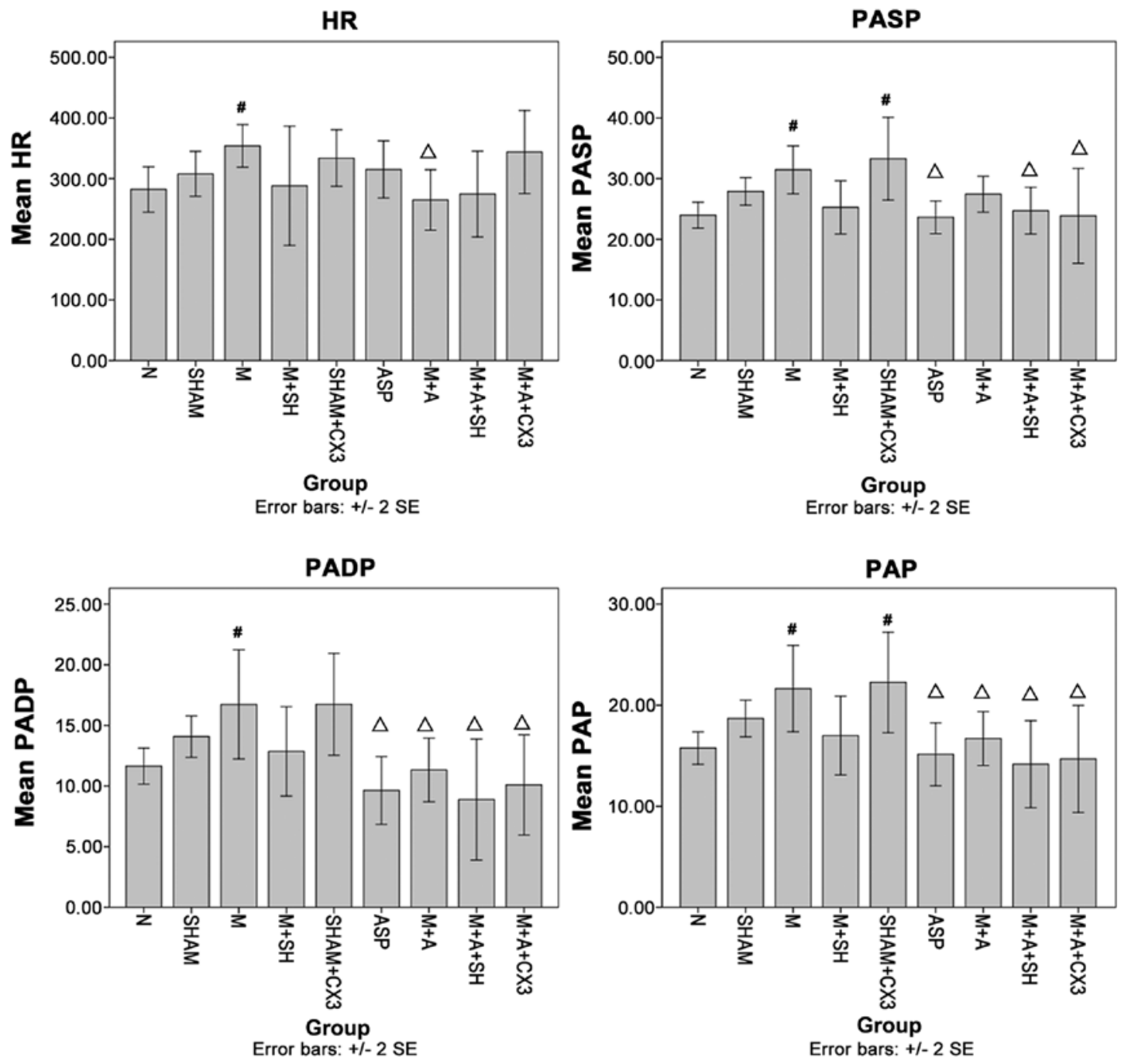

Figure 2. Detection of pulmonary artery pressure. ${ }^{~} \mathrm{P}<0.05$ compared with group $\mathrm{N} ;{ }^{\triangle} \mathrm{P}<0.05$ compared with group M. PASP, pulmonary arterial systolic pressure; PADP, pulmonary artery diastolic pressure ; PAP, pulmonary arterial pressure.

Table I. Pulmonary pathology as detected by hematoxylin and eosin (H\&E).

Group

Pathological change

Group N

Clear pulmonary structure, normal alveolar structure, no evident inflammatory cell infiltration in pulmonary interstitial fibrosis, occasional inflammation in airways and blood vessesl, no formation of thromboembolism in blood vessels

Group Sham, ASP

and Sham $+\mathrm{CX} 3$

Group M

Group M+SH

Group M+ASP

Group M+ASP+SH

Group $\mathrm{M}+\mathrm{ASP}+\mathrm{CX} 3$
Same as normal group, less inflammatory cell infiltration in bronchus and blood vessels and pulmonary interstitial fibrosis (granulocytes, lymphocytes, and eosinophilic granulocytes), no evident formation of thromboembolism in blood vessels

Mixed thrombus and coagulation in the pulmonary artery, evident vascular endothelial loss, alveolar septal thickening and swelling, pulmonary hemorrhage, severe inflammatory cell infiltration in the bronchus and blood vessels and pulmonary interstitial fibrosis, or even pulmonary abscess

Part of embolism in pulmonary artery dissolved, revascularization, intravascular subcutaneous hyperplasia with slight inflammation, less number of thrombogenesis, good thrombolytic effect Good thrombolytic effect, evident vascular endothelial hyperplasia, severe inflammation Good thrombolytic effect, less inflammatory response

Good thrombolytic effect, more inflammatory response 


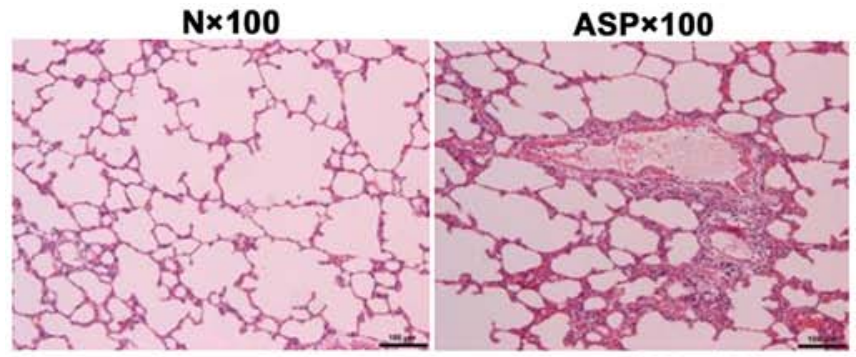

Sham $\times 100$
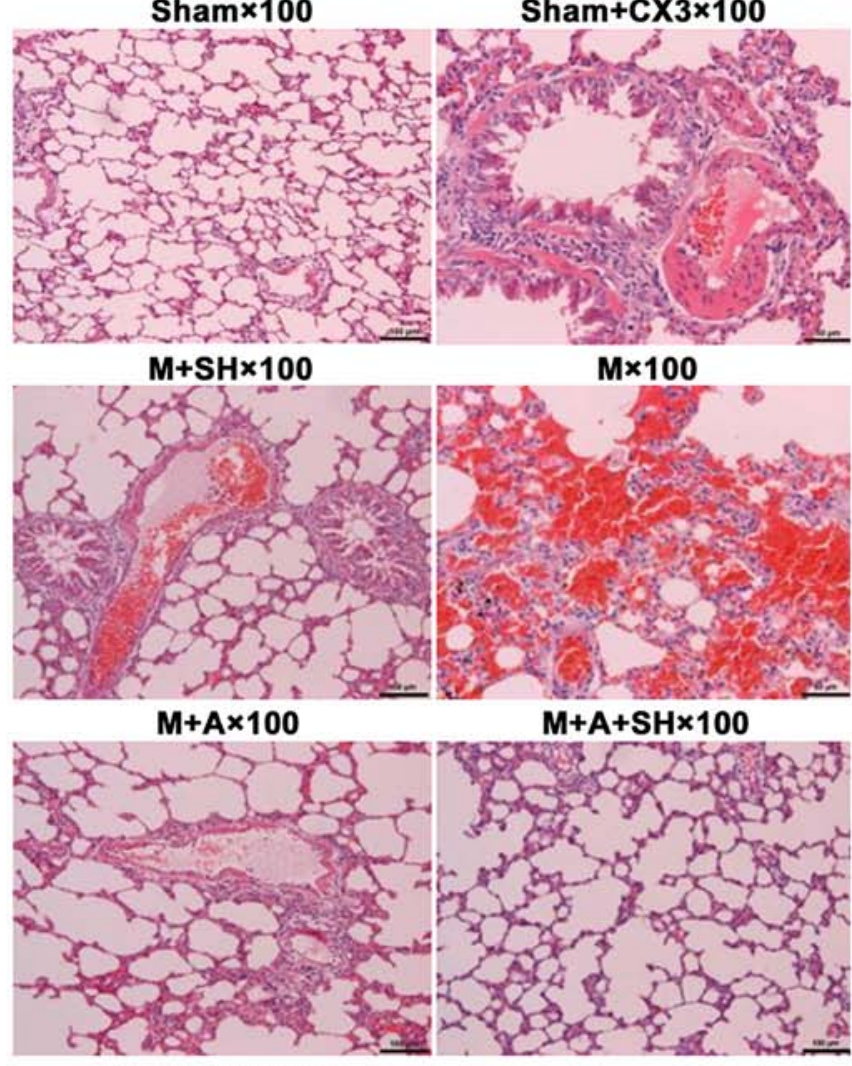

$M+A+C \times 3 \times 100$

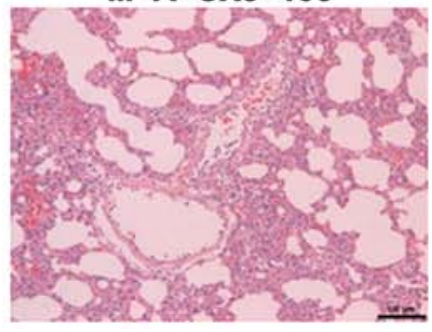

Figure 3. Lung pathology (magnification, x100).

Compared with group $\mathrm{N}$, TNNI3 in group $\mathrm{M}+\mathrm{SH}$ was significantly increased $(\mathrm{P}<0.05)$. Compared with group $\mathrm{M}$, no significant difference was observed.

Compared with group N, BNP in group M was significantly increased $(\mathrm{P}<0.05)$. Compared with group $\mathrm{M}, \mathrm{BNP}$ in groups $\mathrm{N}$, Sham, $\mathrm{M}+\mathrm{SH}, \mathrm{ASP}, \mathrm{M}+\mathrm{A}+\mathrm{SH}$ and $\mathrm{M}+\mathrm{A}+\mathrm{CX} 3$ was significantly decreased $(\mathrm{P}<0.05)$.

Compared with group N, D2D in groups $\mathrm{M}$ and $\mathrm{M}+\mathrm{SH}$ was significantly increased $(\mathrm{P}<0.05)$. Compared with group $\mathrm{M}$, $\mathrm{D} 2 \mathrm{D}$ in groups $\mathrm{N}$ and $\mathrm{M}+\mathrm{A}+\mathrm{SH}$ was significantly decreased $(\mathrm{P}<0.05)$.

Coexpression of CX3CL1/CX3CR1 and CX3CL1/NF- $\mathrm{CB}$ as detected by laser confocal scanning microscopy. The positive
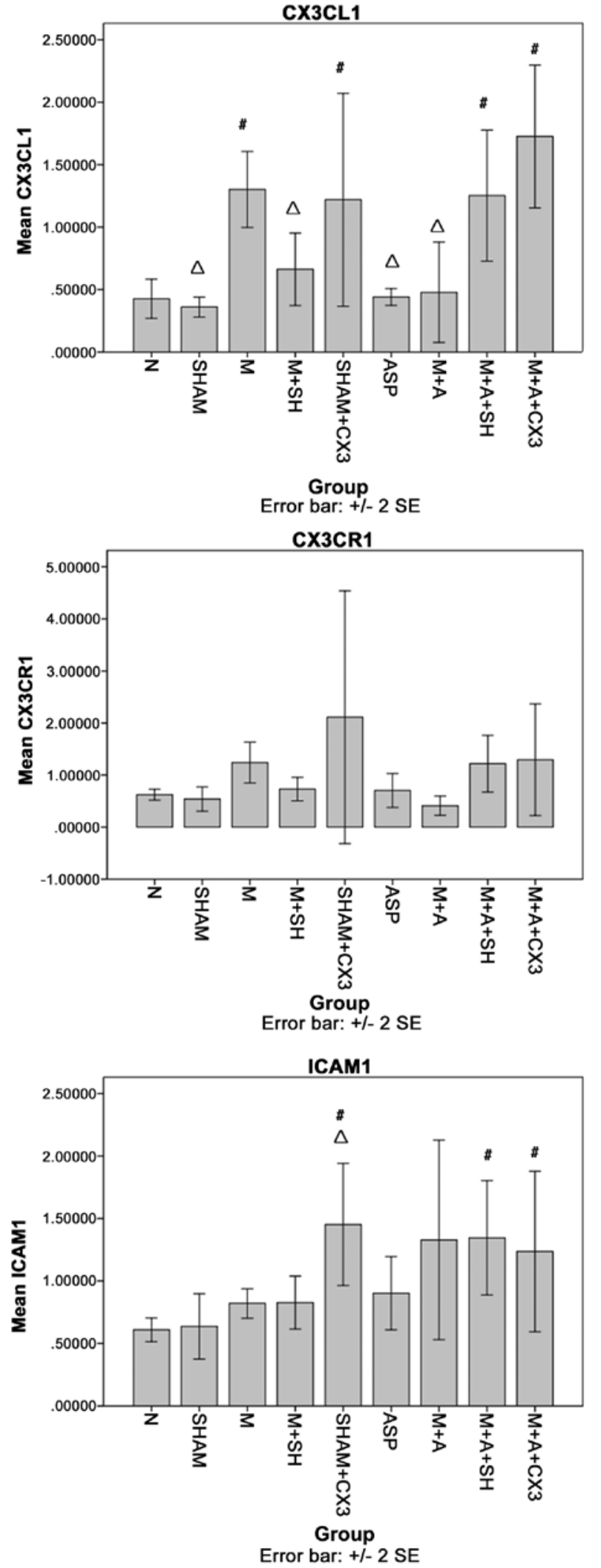

Figure 4. CX3CL1, CX3CR1 and intercellular adhesion molecule-1 (ICAM-1) in the pulmonary tissue as detected by PCR. ${ }^{~} \mathrm{P}<0.05$ compared with group $\mathrm{N}$; ${ }^{\wedge} \mathrm{P}<0.05$ compared with group $\mathrm{M}$.

color of immunofluorescence indicated that CX3CL1 (red) and CX3CR1 (green) were mainly expressed in the cytoplasm and cytomembrane. NF- $\kappa \mathrm{B}$ (green) was mainly expressed in the cytoplasm, and rarely expressed in the cell nucleus. As shown 



Figure 5. Serum thromboxane A2 (TXA2), troponin I type 3 (TNNI3), brain natriuretic peptide (BNP), and D-dimer (D2D) levels as detected by enzymelinked immunosorbent assay (ELISA). ${ }^{*} \mathrm{P}<0.05$ compared with group $\mathrm{N} ;{ }^{\triangle} \mathrm{P}<0.05$ compared with group $\mathrm{M}$.

in Tables II and III and Fig. 6, the fluorescence strength of each group was compared according to the following standard: slight, +; moderate, ++ ; strong, +++ .

Virus infection of the rat pulmonary tissue as observed by laser confocal scanning microscopy. The pulmonary tissue infected by the virus is shown in green color, and the cell nucleus is shown in blue color (Fig. 7).

\section{Discussion}

In the present study, CX3CL1-shRNA AD and CX3CL1overexpression vector were constructed. The study aimed to investigate the influence of CX3CL1 on APE. Compared with a previous study, this study detected pulmonary artery pressure. Although the pressure was not as visual as CTPA, it still could reflect the pressure change after APE. To directly observe the correlation between CX3CL1 in the APE site and CX3CR1 expression and the correlation between the change in the CX3CL1/CX3CR1 signaling pathway and NF- $\mathrm{KB}$ inflammatory pathway, laser confocal scanning microscopy was used. Due to the use of many groups, the experiment was divided into three steps: i) group N, group Sham, group M and group $\mathrm{M}+\mathrm{A}$; ii) group $\mathrm{M}$, group $\mathrm{M}+\mathrm{SH}$ and group $\mathrm{M}+\mathrm{CX} 3$; iii) group $\mathrm{M}+\mathrm{SH}$, group $\mathrm{M}+\mathrm{CX} 3$, group $\mathrm{M}+\mathrm{A}+\mathrm{SH}$ and
Table II. CX3CL1/CX3CR1 expression as detected by doublelabeling immunofluorescence.

Group

Expression strength

$\begin{array}{lc}\text { Group N and ASP } & + \\ \text { Group Sham, Sham+CX3 and M } & ++ \\ \text { Group M+A, M+A+SH and M+A+CX3 } & ++ \\ \text { Group M+SH } & +++\end{array}$

Table III. CX3CL1/NF- $\mathrm{kB}$ expression as detected by doublelabeling immunofluorescence.

Group

Expression strength

Group N, ASP, Sham, and Sham+CX3 $+$

Group $\mathrm{M}+\mathrm{A}, \mathrm{M}+\mathrm{A}+\mathrm{SH}$ and $\mathrm{M}+\mathrm{A}+\mathrm{CX} 3$

$++$

Group $\mathrm{M}$ and $\mathrm{M}+\mathrm{SH}$

$+++$

$\mathrm{NF}-\kappa \mathrm{B}$, nuclear factor- $\kappa \mathrm{B}$ 


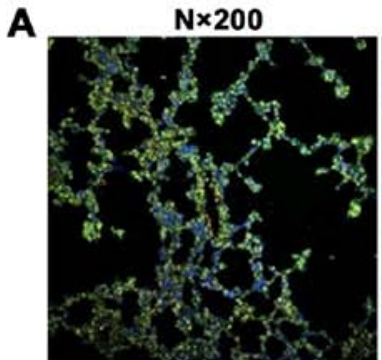

Sham $\times 200$

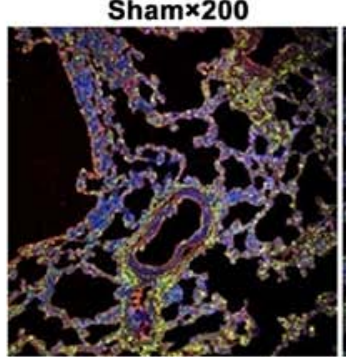

$\mathrm{M}+\mathrm{SH} \times \mathbf{2 0 0}$

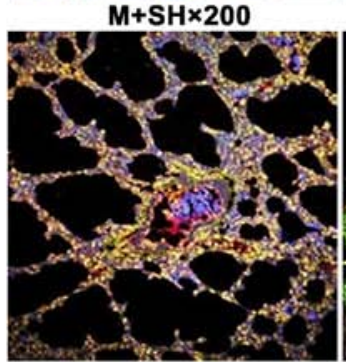

$M+A \times 200$

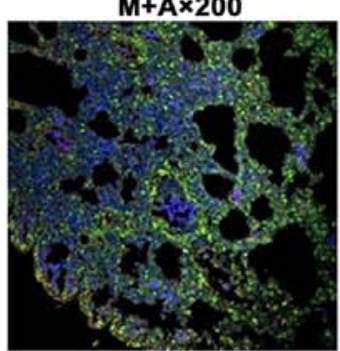

$M+A+C X 3 \times 200$

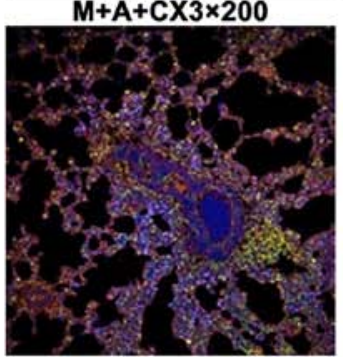

ASP $\times 200$

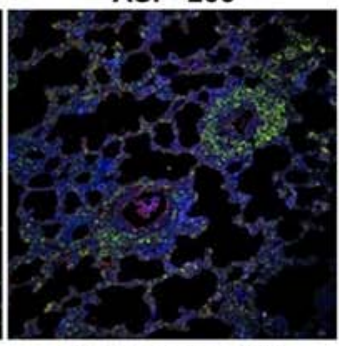

Sham+CX3×200

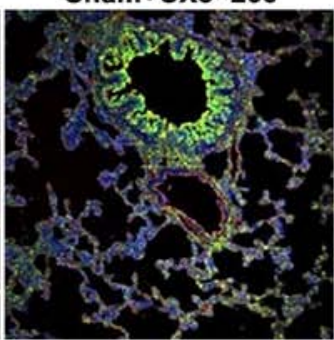

$M \times 200$

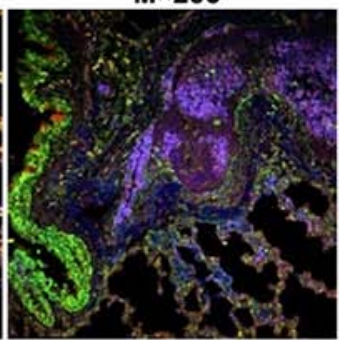

$\mathrm{M}+\mathrm{A}+\mathrm{SH} \times 200$
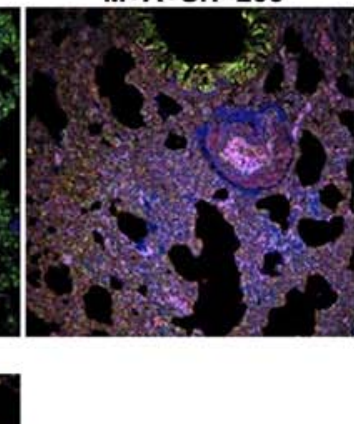

B



Sham $+C X 3 \times 200$

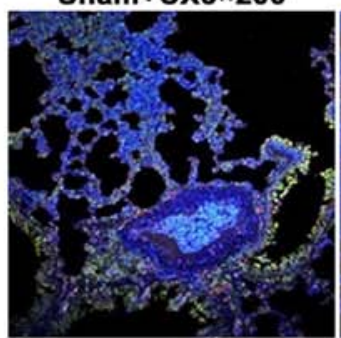

$M \times 200$

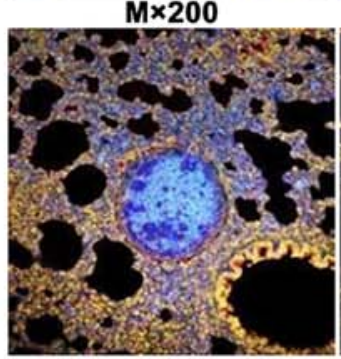

$M+A \times 200$

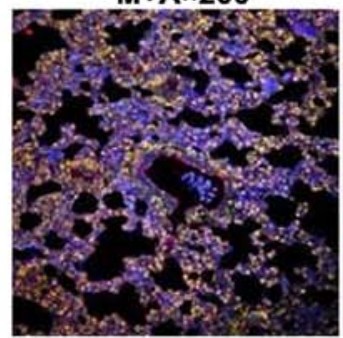

$\mathrm{M}+\mathrm{A}+\mathrm{SH} \times 200$



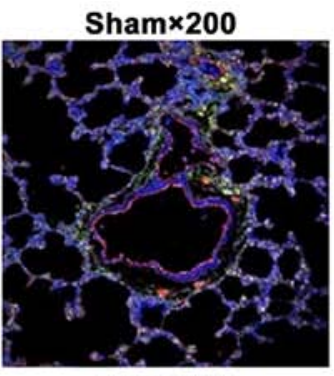

ASP $\times 200$

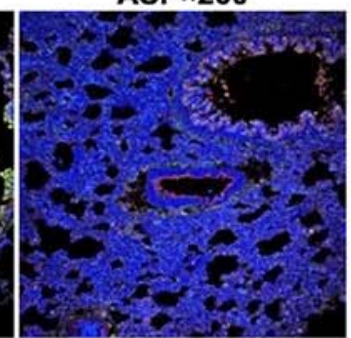

$\mathrm{M}+\mathrm{SH} \times 200$

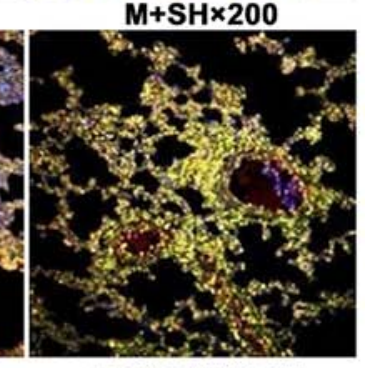

$M+A+C \times 3 \times 200$
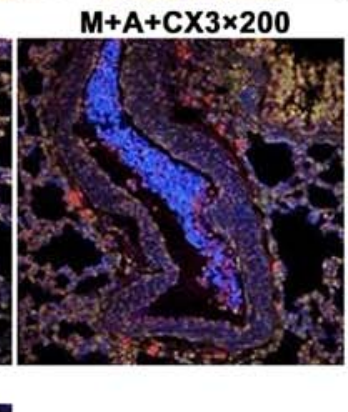

Figure 6. Coexpression of CX3CL1/CX3CR1 and CX3CL1/nuclear factor- $\kappa \mathrm{B}(\mathrm{NF}-\kappa \mathrm{B})$ as detected by laser confocal scanning microscopy. (A) CX3CL1/ CX3CR1 coexpression; magnification $\mathrm{x} 200$. (B) CX3CL1/NF- $\mathrm{B}$ coexpression.

group $\mathrm{M}+\mathrm{A}+\mathrm{SH}$. The first step focused on the drug effect and change in the signaling pathway, the second confirmed the influence of the change in the inflammatory pathway on APE (especially the change in proteins of the signaling pathway), and the third investigated the relationship between the signaling pathway and aspirin (especially the change in the signaling pathway). It was found that aspirin significantly decreased the pulmonary artery pressure, improved pathological changes in the embolism, and decreased the expression of the CX3CL1/CX3CR1 and CX3CL1/NF- $\kappa$ B signaling pathways. Moreover, the AD overexpression CX3CL1 vector aggravated the inflammatory changes in rats with APE, which were improved by aspirin. However, AD CX3CL1 intervention decreased this change, and its combination with aspirin significantly improved the APE changes.

The presemt study explored the important role of the CX3CL1/CX3CR1 signaling pathway in the occurrence of APE as well as improvement in APE changes by aspirin via the signaling pathway. Therefore, pulmonary artery pressure, pulmonary H\&E and ELISA were used to quantitatively detect TNNI3, BNP and D2D levels in rat serum. The limitation of the study was that APE was mainly a mechanical obstruc- 


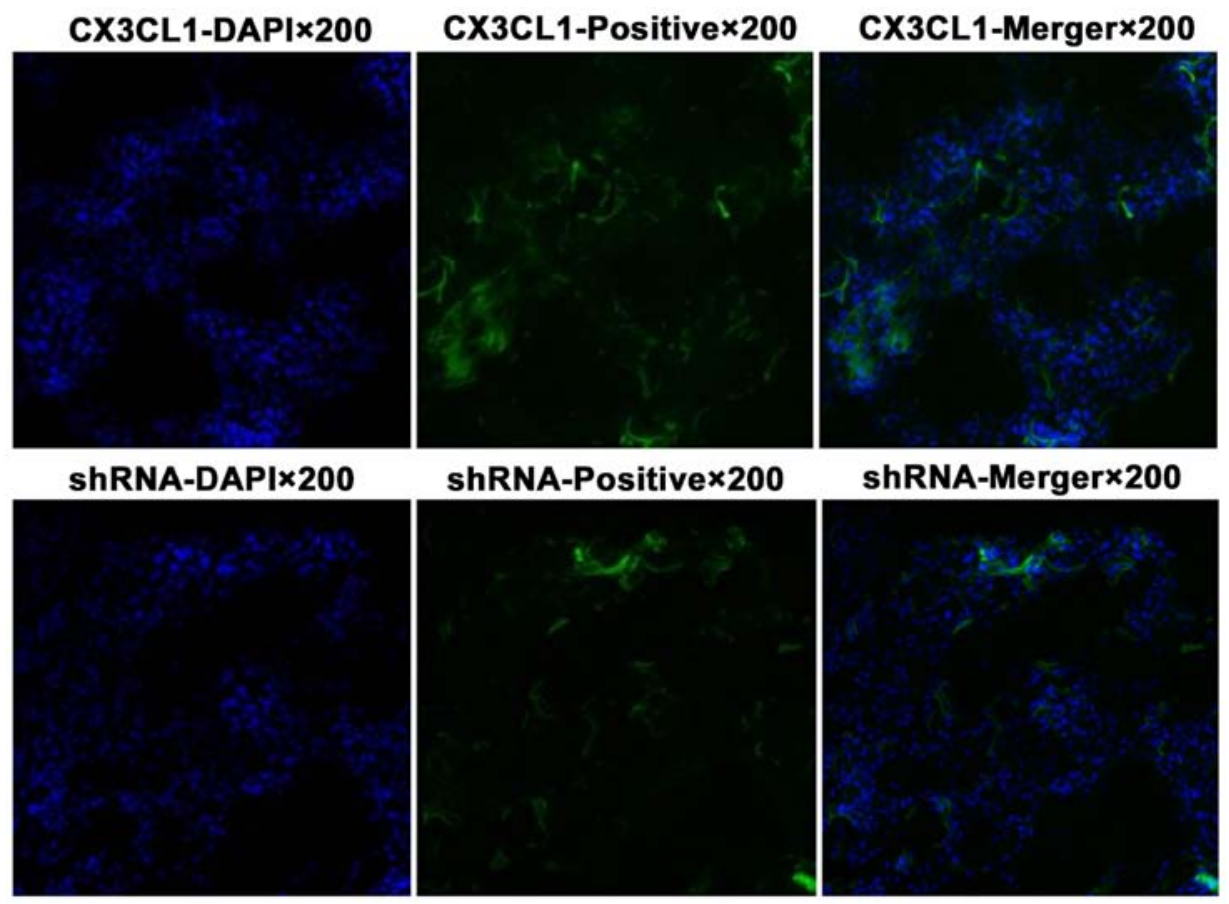

Figure 7. Virus infection of the rat pulmonary tissue observed by laser confocal scanning microscopy.

tion of the pulmonary artery; neurohumoral (inflammatory mediator) control was not the key factor, and hence should not be emphasized, or a disconnection between experimental findings and clinical practice would result.

If therapy for APE is effective, it should significantly decrease the pulmonary artery pressure. When APE occurs, pulmonary artery pressure is increased. The present study found that HR, PASP, PADP and PAP in group M were significantly increased. Therefore, it was believed that the APE model was successful from the aspect of hemodynamics. The HR in group M+A was significantly decreased compared with group $\mathrm{M}$, suggesting that aspirin took effect on APE. The pulmonary artery pressures in group $\mathrm{M}+\mathrm{A}+\mathrm{SH}$ and group $\mathrm{M}+\mathrm{A}+\mathrm{CX} 3$ was significantly decreased, indicating no overexpression or inhibition of CX3CL1; aspirin decreased the pulmonary artery pressure. It was confirmed by pulmonary H\&E detection that only APE was affected by aspirin. Irrespective of the expression or inhibition of CX3CL1, the degree of APE and inflammation was less. The prognosis of APE is related to TnT, BNP and D2D (8). Therefore, these three indicators were used in the present study. After successful APE modeling, serum BNP and D2D were significantly increased. Furthermore, BNP was significantly decreased in $\mathrm{M}+\mathrm{SH}, \mathrm{M}+\mathrm{A}+\mathrm{SH}$ and $\mathrm{M}+\mathrm{A}+\mathrm{CX} 3$, and $\mathrm{D} 2 \mathrm{D}$ was significantly decreased in $\mathrm{M}+\mathrm{A}+\mathrm{SH}$, suggesting that the inhibition of CX3CL1 could improve the pathology of APE.

The European Society of Cardiology reported that APE is the most severe clinical manifestation of venous thromboembolism (VTE) (8). The basic process of APE includes mechanical obstruction. Pulmonary artery spasm contraction caused by neurohumoral factor (mainly inflammatory mediator) also plays an important role, especially within a short time. It mainly involves fibrous proteins and aggregated blood platelets, and also infiltration of various inflammatory cells. They continuously release a series of inflammatory mediators such as A2 (TXA2) (9) to shrink the pulmonary artery. More attention has been paid to the first step, and less to the second step.

CX3CL1 (fractalkine) is a chemotactic factor containing 373 amino acids. It possesses adhesive and chemotactic activity. It is the only member of the CX3C family (10), and can combine with a specific receptor CXCCR1, mediating the intimate adhesion of inflammatory cells and vascular endothelium cells. CX3CL1 plays an important role in the recruitment of inflammatory cells on the vascular wall and injury of endothelial cells $(11,12)$. It was reported that TNF- $\alpha$ could influence the CX3CL1/CX3CR1 inflammatory signaling pathway (13), which was confirmed in a previous study (5). It was also demonstrated that the CX3CL1/CX3CR1 signaling pathway exists in atherosclerosis (14), and CX3CL1 plays a role in high pulmonary artery pressure combined with high airway pressure (15). However, still no systematic study exists on the mechanism underlying the involvement of CX3CL1/CX3CR1 in APE.

It was also confirmed that CX3CL1 was significantly increased in APE. Aspirin could inhibit the expression, as shown in this study. CX3CL1 in group Sham+CX3 was significantly increased and that in group $\mathrm{M}+\mathrm{SH}$ was significantly decreased, suggesting that the preparations of CX3CL1 AD and shRNA AD were successful.

ICAM-1 is a member of the immunoglobulin superfamily (16). It is mainly expressed in neuronal cells, immune cells, vascular endothelium cells, epithelial cells, and glial cells. It is one of the important leukocyte-endothelial cell adhesion molecules, and is involved in intracellular and cell-matrix signal exchange, mediating adhesion, recognition, activation, proliferation, differentiation, inflammatory reaction and damage repair. After CX3CL1 overexpression in group Sham, the ICAM-A level was significantly higher than that in group $\mathrm{N}$ and group $\mathrm{M}$, indirectly suggesting that CX3CL1 could stimulate the secretion of ICAM-1. 
The TXA2 level in rats with APE was significantly increased, and the levels in groups $\mathrm{M}+\mathrm{SH}, \mathrm{M}+\mathrm{A}$ and $\mathrm{M}+\mathrm{A}+\mathrm{SH}$ were significantly decreased. This indicated that aspirin could decrease TXA2 secretion after inhibiting CX3CL1 expression.

The coexpression of CX3CL1/CX3CR1 and CX3CL1/ $\mathrm{NF}-\mathrm{kB}$ as detected by double immunofluorescent staining suggested increased expression of the aforementioned factors.

Therapy for APE includes streptokinase, urokinase, recombinant tissue plasminogen activator thrombolysis, low-molecular-weight heparin and new oral anticoagulants $(1,8,17)$. The selection of aspirin was due to the inflammatory response after the occurrence of APE. It could irreversibly inhibit epoxidase and further inhibit the formation of thromboxane A2 in blood platelets. It could also inhibit the activation of NF- $\mathrm{kB}$ and exert anti-inflammatory effects. As nonsteroidal anti-inflammatory drugs are not specific, their high concentration may effectively inhibit inflammatory factors such as NF- $\kappa B(18,19)$. A previous study found that aspirin could inhibit NF- $\kappa B$ expression in APE (5). Aspirin inhibits CX3CL1/CX3CR1 expression $(20,21)$. It can be safely applied in APE or for preventing deep vein thrombosis $(22,23)$. The daily aspirin dose was reported to be $325 \mathrm{mg}$ for 14 days. Prevention and treatment of VTE was safe, thus the dose of aspirin was increased in the present study (24). This study demonstrated that aspirin improved the pathological changes in rats with APE via the CX3CL1/CX3CR1 signaling pathway.

Future studies should investigate the effect (and its underlying mechanism) of CX3CL1 on thrombogenesis by influencing the damage of vascular endothelium cells and inflammatory response.

\section{Acknowledgements}

The present study was funded by the Medical and Health Platform Program of Zhejiang Province (key support) (grant no. 2015ZDA022), Zhejiang Provincial Program for the Cultivation of High-Level Innovative Health Talents (2014-108) and the Natural Sciences Fund of Zhejiang Province (grant nos. LY17H290006 and LY12H29005).

\section{References}

1. Geerts WH, Bergqvist D, Pineo GF, Heit JA, Samama CM, Lassen MR and Colwell CW: Prevention of venous thromboembolism: American college of chest physicians evidence-based clinical practice guidelines (8th edition). Chest 133 (Suppl 6): 381S-453S, 2008.

2. Cohen AT, Agnelli G, Anderson FA, Arcelus JI, Bergqvist D, Brecht JG, Greer IA, Heit JA, Hutchinson JL, Kakkar AK, et al; VTE Impact Assessment Group in Europe (VITAE): Venous thromboembolism (VTE) in Europe. The number of VTE events and associated morbidity and mortality. Thromb Haemost 98 756-764, 2007.

3. Yang Y, Liang L, Zhai Z, He H, Xie W, Peng X and Wang C; Investigators for National Cooperative Project for Prevention and Treatment of PTE-DVT: Pulmonary embolism incidence and fatality trends in chinese hospitals from 1997 to 2008: A multicenter registration study. PLoS One 6: e26861, 2011.

4. Wang L, Wu J, Zhang W, Zhi Y, Wu Y, Jiang R and Yang R: Effects of aspirin on the ERK and PI3K/Akt signaling pathways in rats with acute pulmonary embolism. Mol Med Rep 8: 1465-1471, 2013.

5. Wang LC, Jiang RL, Zhang W, Wei LL and Yang RH: Effects of aspirin on the expression of nuclear factor- $\kappa \mathrm{B}$ in a rat model of acute pulmonary embolism. World J Emerg Med 5: 229-233, 2014.
6. Wang LC, Wu JN, Xia GL, Mao W, Ying RB, Huang LQ and Jiang RL: Effect of aspirin on fractalkine in rats with pulmonary embolism. Trop J Pharm Res 13: 753-760, 2014.

7. Jiang R, Wei L, Zhu M, Wu J and Wang L: Aspirin inhibits

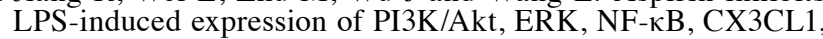
and MMPs in human bronchial epithelial cells. Inflammation 39: 643-650, 2016.

8. Konstantinides S, Torbicki A, Agnelli G, Danchin N, Fitzmaurice D, Galiè N, Gibbs J, Huisman M, Humbert M, Kucher N, et al; SEC Working Group for the ESC 2014 Guidelines on the Diagnosis and Management of Acute Pulmonary Embolism; Expert Reviewers for the ESC 2014 Guidelines on the Diagnosis and Management of Acute Pulmonary Embolism; SEC Clinical Practice Guidelines Committee: Comments on the 2014 ESC Guidelines on the diagnosis and management of acute pulmonary embolism. Rev Esp Cardiol (Engl Ed) 68: 10-16, 2015.

9. Schmeck J, Koch T, Patt B, Heller A, Neuhof H and van Ackern K: The role of endothelin-1 as a mediator of the pressure response after air embolism in blood perfused lungs. Intensive Care Med 24: 605-611, 1998.

10. Bazan JF, Bacon KB, Hardiman G, Wang W, Soo K, Rossi D, Greaves DR, Zlotnik A and Schall TJ: A new class of membranebound chemokine with a CX3C motif. Nature 385: 640-644, 1997.

11. Todorova D, Sabatier F, Doria E, Lyonnet L, Vacher Coponat H, Robert S, Despoix N, Legris T, Moal V, Loundou A, et al: Fractalkine expression induces endothelial progenitor cell lysis by natural killer cells. PLoS One 6: e26663, 2011.

12. Matsumiya $T$, Ota $K$, Imaizumi $T$, Yoshida $H$, Kimura $H$ and Satoh K: Characterization of synergistic induction of CX3CL1/fractalkine by TNF-alpha and IFN-gamma in vascular endothelial cells: An essential role for TNF-alpha in post-transcriptional regulation of CX3CL1. J Immunol 184: 4205-4214, 2010.

13. Szukiewicz D, Kochanowski J, Mittal TK, Pyzlak M, Szewczyk G and Cendrowski K: CX3CL1 (fractalkine) and TNF $\alpha$ production by perfused human placental lobules under normoxic and hypoxic conditions in vitro: The importance of CX3CR1 signaling. Inflamm Res 63: 179-189, 2014.

14. Apostolakis S and Spandidos D: Chemokines and atherosclerosis: Focus on the CX3CL1/CX3CR1 pathway. Acta Pharmacol Sin 34: 1251-1256, 2013

15. Ars C, Thurion P, Delos M, Sibille Y and Pilette C: Small airway obstruction in severe pulmonary arterial hypertension correlates with increased airway $\mathrm{CD} 8^{+} \mathrm{T}$-cells and fractalkine expression. Eur Respir J 34: 1494-1496, 2009.

16. Ostrowski RP, Jadhav V, Chen W and Zhang JH: Reduced matrix metalloproteinase- 9 activity and cell death after global ischemia in the brain preconditioned with hyperbaric oxygen. Acta Neurochir Suppl (Wien) 106: 47-49, 2010.

17. Wang C, Zhai Z, Yang Y, Cheng Z, Ying K, Liang L, Dai H, Huang K, Lu W, et al: Inverse relationship of bleeding risk with clot burden during pulmonary embolism treatment with LMW heparin. Clin Respir J 10: 596-605, 2016.

18. Bhattacharyya S, Ghosh S and Sil PC: Amelioration of aspirin induced oxidative impairment and apoptotic cell death by a novel antioxidant protein molecule isolated from the herb Phyllanthus niruri. PLoS One 9: e89026, 2014.

19. Yamamoto $\mathrm{Y}$ and Gaynor RB: Therapeutic potential of inhibition of the NF-kappaB pathway in the treatment of inflammation and cancer. J Clin Invest 107: 135-142, 2001

20. Szukiewicz D, Wojciechowska M, Bilska A, Stangret A, Szewczyk G, Mittal TK, Watroba M and Kochanowski J: Aspirin action in endothelial cells: Different patterns of response between chemokine CX3CL1/CX3CR1 and TNF- $\alpha$ /TNFR1 signaling pathways. Cardiovasc Drugs Ther 29: 219-229, 2015.

21. Guo Y, Apostalakis S, Blann AD and Lip GY: Plasma CX3CL1 levels and long term outcomes of patients with atrial fibrillation: The West Birmingham Atrial Fibrillation Project. Cerebrovasc Dis 38: 204-211,2014.

22. Ogonda L; Hill J; Doran E; Dennison J; Stevenson M and Beverland D: Aspirin for thromboprophylaxis after primary lower limb arthroplasty: Early thromboembolic events and 90 day mortality in 11,459 patients. Bone Joint J 98-B: 341-348, 2016.

23. Braithwaite I, Dunbar L, Eathorne A, Weatherall $M$ and Beasley R: Venous thromboembolism rates in patients with lower limb immobilization after Achilles tendon injury are unchanged after the introduction of prophylactic aspirin: Audit. J Thromb Haemost 14: 331-335, 2016

24. Kaye ID; Patel DN; Strauss EJ; Alaia MJ; Garofolo G; Martinez A and Jazrawi LM: Prevention of venous thromboembolism after arthroscopic knee surgery in a low-risk population with the use of aspirin. A randomized trial. Bull Hosp Jt Dis (2013) 73: 243-248, 2015. 